GEORGETOWN SCIENTIFIC RESEARCH JOURNAL
Volume One Edition One February 2021

\title{
Policy Brief: Comparison and Recommendations for State COVID-19 Responses of New Mexico and Utah
}

Ariyand Aminpour 


\title{
Policy Brief: Comparison and
}

\section{recommendations for state COVID-19}

\section{responses of New Mexico and Utah}

\author{
Ariyand Aminpour \\ Department of Biology, Georgetown University, Washington, DC \\ E-mail:ama412@georgetown.edu
}

\begin{abstract}
New Mexico has seen a steady increase in SARS-CoV-2 (COVID-19) cases, but compared to Utah, New Mexico has kept case numbers low due to important mitigation policies passed by Governor Michelle Grisham. The goals and priorities of each state's governor contributed to the policies and severity of restrictions in each state. ${ }^{1,2}$ Governor Grisham's mask, mass gathering, and interstate quarantine policies are restrictions that she deems necessary in order to mitigate the spread and save lives. ${ }^{2}$ Governor Gary Herbert has valued economic recovery as opposed to virus mitigation, which is reflected in his lenient restrictions. ${ }^{2}$ In the immediate future, Governor Cox, Governor Herbert's successor as of January, should enact the same mask, mass gathering, and interstate quarantine policies as New Mexico; both states should then reassess the list of states that people need to quarantine from, given that 21 states hit records for 7day average of COVID-19 cases, as of October 11, in order to get transmission under control. ${ }^{3}$ Additionally, if COVID-19 transmission is slowed, mass gathering restrictions can be reassessed to allow for larger gatherings but should stay tightly restricted until that point.
\end{abstract}

Keywords: COVID-19, Policies, New Mexico, Utah

\section{Background}

The two states being compared are New Mexico and Utah. These two states were chosen for comparison because they are two adjacent states in the U.S. with differing gubernatorial policy responses to the COVID-19 pandemic. The gubernatorial responses are important policy actions to observe and study, regarding the pandemic in the U.S. This is because there has been limited and fractured federal response to the pandemic, leaving much of the leadership to pandemic response in the hands of state governors. ${ }^{4}$ Governor Michelle Grisham of New Mexico has enforced stricter policies, such as a statewide mask mandate, in order to slow the spread of the SARS-CoV-2 virus in New Mexico. ${ }^{5}$ Governor Gary Herbert had not enacted the same statewide level policies to slow the spread of the virus, enacting policies that affect only certain locations and counties. ${ }^{2,}{ }^{6}$ Due to the differences 


\section{https://doi.org/10.48091/LYQC3557}

between the two policy paths, the states have seen quite different results in terms of COVID-19 mitigation. $^{7}$ The differences in New Mexico and Utah's gubernatorial policies regarding COVID19 demonstrate the various choices states are taking; the choice is either maximizing mitigation of the virus through statewide, strict measures or giving more freedoms to citizens, while slowing the virus's spread to an extent and ensuring the economy is able to stay open. These two adjacent states are an example of these two policy strategies, and the comparison of the outcomes of these policies serve to show which plan is more beneficial to states and the subsequent effects the laws have on lowering daily cases.

\section{Comparison of Epidemiology, Policies, and Outbreaks}

Compared to Governor Herbert's policies, Governor Grisham's COVID-19 policies have been far more stringent. New Mexico's stricter policies have translated into comparatively lower current and overall COVID-19 infections throughout the pandemic. ${ }^{7}$ Governor Grisham passed a statewide mask mandate on May 15, 2020, requiring a face covering in public at all times except when eating, drinking, exercising, or advised otherwise by a physician. ${ }^{5}$ The strict statewide face covering mandate was instituted to slow the spread of COVID-19 following evidence that the disease can be transmitted through spit and water droplets. Face coverings create a cloth barrier between people, and in the case of coughing, sneezing, or spreading water particles while speaking, the covering would reduce transmission of the virus. ${ }^{8}$ A study measuring the effectiveness of U.S. mask mandates showed a significant decline in the growth rate of COVID19 cases after a public face covering mandate was issued, further demonstrating the importance of Governor Grisham's decision. ${ }^{9}$ Conversely, Governor Herbert instituted a policy for mandatory use of face coverings within state buildings. ${ }^{6}$ This was later paired with a mask requirement in K-12 schools. ${ }^{10}$ Utah's new Governor, Spencer Cox, who has replaced Governor Herbert, said in a recent debate that Utah had yet to enact a statewide mask mandate because it was unlikely to be followed and that "it doesn't make that much of a difference". ${ }^{11}$ Cox's statement directly contradicts the findings in the previous study; these included that the growth rate of the virus continued to decline after a mask mandate was enacted and that U.S. states with statewide face covering mandates had a greater decline in the growth rate of COVID-19 compared to states that did not sign the same mandates. ${ }^{9}$

Another difference in the choices made by the two governors is the capacity restrictions passed regarding mass gatherings. Suspension of mass gatherings is a mitigation strategy that helps early in pandemics when medical countermeasures may not be adequately researched and available for use. ${ }^{12}$ Governor Grisham has passed a policy on mass gatherings that limits an enclosed space gathering to 5 people; this law lasted from March 23 to August 28, when it was increased to a limit of 10 people on August 29, 2020.. ${ }^{13}$ Since large gatherings can facilitate transmission due to the lack of social distancing, this order was meant to limit such gatherings and slow the spread of COVID-19. ${ }^{12}$ In May, Governor Herbert passed a law that limited mass gatherings to 20 individuals, a policy that was soon replaced by a reopening plan in June 2020, prioritizing the reopening of businesses. ${ }^{2}$ Medical experts and epidemiologists were cut out of the process of drafting reopening guidelines, which led to policies that allowed indoor gatherings of 3,000 people and outdoor gatherings of 6,000 people., ${ }^{24}$ Governor Herbert claimed that the relaxed COVID-19 mitigation policies on mass gatherings avoided enacting overly strict policies on less affected counties in 


\section{https://doi.org/10.48091/LYQC3557}

Utah. His decision led to a ranking system in which counties were rated by transmission risk (low, medium, and high), with the lowest tier counties being allowed gatherings of up to $3,000 .^{2}$ The choice to allow for such large mass gatherings most likely contributed to a rise in cases in Utah, which can be seen in the uptick of cases during the same time frame. Between June 1 and July 18, daily cases state-wide rose from 197 to $858 .^{7}$ This is because mitigation of a pandemic level virus, like COVID-19, is impossible without stopping mass gatherings through policy choices. ${ }^{12}$ In comparison, with New Mexico's more restrictive policies in place, daily cases state-wide only rose from 111 to 280 between June 1 and July 18. ${ }^{7}$

A third difference in gubernatorial policy is the differences in quarantine requirements for air travelers to each state. Air travel is a large source of importation of COVID-19 to new areas, especially through asymptomatic travelers. ${ }^{15}$ Governor Grisham passed a quarantine policy, on March 27, 2020, which requires air travelers to New Mexico to self-quarantine for a minimum of 14 days. ${ }^{16}$ The policy was adapted to limit COVID-19 transmission from individuals arriving from states with high transmission rates and daily case counts and prevent unnecessary deaths due to such spread. ${ }^{1}$ This mitigation strategy is fueled by CDC guidance indicating that air travel can lead to COVID-19 infection due to extended time spent in security lines and terminals, as well as the lack of social distancing on crowded flights. ${ }^{17}$ Conversely, Governor Herbert passed a policy on April 8 dictating that any individuals, 18 years of age, arriving by air or road must fill out a declaration of entry form but does not require quarantine of individuals. ${ }^{18}$ The goal of this policy was to contact trace individuals coming to Utah who could possibly spread COVID-19. The aim was to allow citizens to enter Utah without forcing them to quarantine upon arrival, but this is a less effective policy measure than quarantining due to the fact that Utah does not have enough contact tracers to handle the current active case numbers in the state. ${ }^{19}$ There are currently 8.32 total contract tracers per 100,000 residents in the state of Utah. ${ }^{19}$

Governor Grisham's three outlined policies enacted to slow COVID-19 were strict due to the fact that she believed policies requiring quarantine, masks, and mass gathering restrictions limited transmission pathways of the virus; she believed this was essential to save lives and reduce hospitalizations that were overwhelming state hospitals. ${ }^{1}$

Governor Herbert chose not to make uniformly strict and statewide policy decisions, since some counties were less affected by the virus. ${ }^{2}$ However, the virus has not been and cannot be contained by county borders, so uniform policies are needed to ensure transmission does not continue to flare up in some parts of the state, with a possibility of spreading to the rest. Governor Herbert made policy decisions based on state hospitals' capacities to handle cases, instead of effectiveness of mitigation strategies. ${ }^{2}$ Moreover, Governor Herbert also drafted policies based on the capabilities of state contact tracers, emphasizing that the policies were focused on the state's capacity to respond to outbreaks, rather than mitigating transmission. ${ }^{2}$ Governor Herbert's policy decisions, such as allowing up to 3,000 individual mass gatherings inside, were aimed at aiding businesses that could not survive under lowered capacity limits. ${ }^{2}$ Since these laws were passed, Utah's new unemployment claims fell by $78 \%$ in early July, in comparison to the peak in claims that occurred in April. ${ }^{2}$ In July 2020, Utah's unemployment rate was at $4.5 \%$, after reaching $10.4 \%$ in April. ${ }^{21}$ In comparison, New Mexico's unemployment rate reached $12.7 \%$ in July $2020 .^{21}$ Utah's policies have lowered the unemployment rate and prioritized economic recovery. However, this recovery has occurred at the expense of mitigating the virus. 


\section{https://doi.org/10.48091/LYQC3557}

The effectiveness of Governor Grisham's policies can be seen in the state's case numbers; the outcome of New Mexico's policies has led to lower case numbers, compared to Utah. ${ }^{7}$ New Mexico had 485 daily cases of COVID-19, as of October 9, with a seven day average of 320 cases; Utah had 1,332 daily cases, as of October 9, with a seven day average of 1,162 cases. $^{7}$

\section{Proposal for Future Coronavirus Policy}

In the next month, Utah should echo the stricter policies of New Mexico and start by passing a statewide policy that makes facial coverings necessary in public, in order to be in accordance with CDC guidance. ${ }^{8} \mathrm{~A}$ mask mandate would be beneficial for lowering numbers in the state because evidence has found that a mandate can slow the growth rate of COVID-19, with the decline in cases increasing the longer the mandate is in place (Lyu and Wehby 2020). Additionally, Utah should require travelers coming from out of state to quarantine for 14 days because 21 states have reached their records for 7-day average of new COVID-19 cases, as of October 11. ${ }^{3}$ Travelers, especially those arriving via air travel, from outside the borders of Utah can possibly spread COVID19 through asymptomatic transmission, introducing the virus to new populations and parts of the state. ${ }^{15}$ Since cases are rising in states across the U.S., travelers from outside the borders of Utah pose a risk to Utah's citizens; the need for a mandatory quarantine policy is further intensified because of Utah's lacking contact tracing workforce. ${ }^{19}$ Moving forward, if states are able to get case counts under control, Utah and New Mexico should reassess the transmission risk of some states and make an updating list of states from which travelers are allowed to enter without quarantine, due to the low case count of the state from which travelers come. As mentioned, mass gathering restrictions are necessary to slow the spread of a pandemic, and therefore Utah should institute a statewide mass gathering restriction of 10 people, similar to New Mexico. ${ }^{12}$ Mass gatherings have been shown to exacerbate the spread of COVID-19, as the virus transmits easily in crowds where social distancing of six feet apart is not followed or attainable. ${ }^{12}$ As time progresses, New Mexico and Utah can reassess case counts in their states, and if the virus has been controlled and spread mitigated through policy decisions, they could possibly increase the number of individuals per mass gathering.

\section{Conclusions}

As shown, Governor Grisham's mask, mass gathering, and interstate quarantine policies have contributed to the amount of COVID-19 cases in New Mexico being lower than that of Utah. Governor Herbert's policies reflect the fact that the governor values economic recovery over virus mitigation. ${ }^{22}$ Utah's governor should implement the same three policies outlined for New Mexico, in order to better mitigate the spread of COVID19. If instituted, both states can reassess the strictness of their interstate quarantine, updating the list of states that people need to quarantine from; this should only occur if states can decrease case numbers. With the hope of more research and COVID-19 control, mass gatherings may be reassessed and possibly relaxed depending on Utah and New Mexico's ability to slow the spread of COVID-19.

\section{References}

1. Bryan, Susan. 2020. "New Mexico Governor Renews Restrictions as Virus Cases Rise." October 14, 2020. https://apnews.com/article/virus-outbreakpublic-health-michelle-lujan-grisham-newmexicob51b771a974484857b4bd59407b19870.

2. Simon, Lisa Song, Mollie. 2020. "Politicians and Business Interests Pushed Health Officials 


\section{https://doi.org/10.48091/LYQC3557}

Aside to Control Reopening. Then Cases Exploded.” ProPublica. July 21, 2020. https://www.propublica.org/article/politiciansand-business-interests-pushed-healthofficials-aside-to-control-reopening-thencases-

exploded?token=Z80NpH3ypdpU2VX97FRF IzEJC6NBjm2A.

3. Almasy, Steve, Madeline Holcombe, and Dakin Andone. 2020. "US Coronavirus: Covid-19 Deaths Will Rise Almost 80\% by February, Researchers Foresee - CNN." October 15, 2020.

https://www.cnn.com/2020/10/15/health/uscoronavirus-thursday/index.html.

4. Science News Staff, 2020. "The United States Leads in Coronavirus Cases, but Not Pandemic Response.” Science, April 2, 2020. https://www.sciencemag.org/news/2020/04/un ited-states-leads-coronavirus-cases-notpandemic-response.

5. Office of the Governor of New Mexico on Face Coverings. 2020. "Governor Signs Modified, Extended Public Health Order Easing Some Restrictions and Requiring Face Coverings | Office of the Governor - Michelle Lujan Grisham.” May 15, 2020. https://www.governor.state.nm.us/2020/05/15 /governor-signs-modified-extended-publichealth-order-easing-some-restrictions-andrequiring-face-coverings/.

6. Office of the Governor of Utah on Face Coverings. 2020. "Governor Issues Executive Orders | Governor Gary Herbert.” September 4, 2020.

https://governor.utah.gov/2020/09/04/governo r-issues-executive-orders/.

7. COVID AMP. 2020. "COVID AMP." October 16, 2020. https://covidamp.org/model\#UT.

8. CDC Face Covering. 2020a. "Coronavirus Disease 2019 (COVID-19)." Centers for
Disease Control and Prevention. February 11, 2020. https://www.cdc.gov/coronavirus/2019ncov/prevent-getting-sick/cloth-face-coverguidance.html.

9. Lyu, Wei, and George L. Wehby. 2020. "Community Use Of Face Masks And COVID-19: Evidence From A Natural Experiment Of State Mandates In The US.” Health Affairs 39 (8): 1419-25.

https://doi.org/10.1377/hlthaff.2020.00818.

10. Utah Department of Health. 2020. "State Public Health Order Masks in Schools.” https://coronavirusdownload.utah.gov/Governor/UPHO-202010-State-Public-Health-Order-Masks-inSchools.pdf.

11. Eppolito, Sophia. 2020. "Utah Governor Candidates Debate Virus Response, Mask Mandate.” AP NEWS. September 30, 2020. https://apnews.com/article/virus-outbreakutah-pandemics-jon-huntsman-jr-garyherbert1ef7866db4410524288fb84dd266a633.

12. Ebrahim, Shahul H., and Ziad A. Memish. 2020. "COVID-19 - the Role of Mass Gatherings." Travel Medicine and Infectious Disease 34: 101617. https://doi.org/10.1016/j.tmaid.2020.101617.

13. Office of the Governor of New Mexico on Emergency Order. 2020. "Governor Announces Revised Emergency Public Health Order | Office of the Governor - Michelle Lujan Grisham.” August 27, 2020. https://www.governor.state.nm.us/2020/08/27 /governor-announces-revised-emergencypublic-health-order/.

14. ABC4 News. 2020. "Mass Gatherings Can Resume under Updated 'Yellow' Phase Guidelines.” ABCA Utab (blog). June 11, 2020. https://www.abc4.com/coronavirus/massgatherings-can-resume-in-southwest-utah/. 


\section{https://doi.org/10.48091/LYQC3557}

15. Nakamura, Hiroki, and Shunsuke Managi. 2020. "Airport Risk of Importation and Exportation of the COVID-19 Pandemic." Transport Policy 96 (September): 40-47. https://doi.org/10.1016/j.tranpol.2020.06.018.

16. Office of the Governor of New Mexico on Self-Isolation. 2020. "Gov. Lujan Grisham Orders Self-Isolation for Air Travelers to N.M. | Office of the Governor - Michelle Lujan Grisham.” March 27, 2020. https://www.governor.state.nm.us/2020/03/27 Igov-lujan-grisham-orders-self-isolation-forair-travelers-to-n-m/.

17. CDC Travel. 2020b. "Coronavirus Disease 2019 (COVID-19).” Centers for Disease Control and Prevention. February 11, 2020. https://www.cdc.gov/coronavirus/2019ncov/travelers/travel-during-covid19.html.

18. Office of the Governor Of Utah on Travel. 2020. "Governor Issues Executive Order on Inbound Travel | Governor Gary Herbert." April 8, 2020. https://governor.utah.gov/2020/04/09/governo r-issues-executive-order-on-inbound-travel/.

19. Simmons-Duffin, Selena. "COVID-19 Contact Tracing Workforce Barely 'Inching Up' As Cases Surge." NPR. NPR, October 14, 2020. https://www.npr.org/sections/healthshots/2020/10/14/923468159/covid-19contact-tracing-workforce-barely-inching-upas-cases-surge.

20. U.S. Bureau of Labor Statistics. 2020b. "Utah Economy at a Glance." 2020.

https://www.bls.gov/eag/eag.ut.htm.

21. U.S. Bureau of Labor Statistics. 2020a. "New Mexico Economy at a Glance.” 2020. https://www.bls.gov/eag/eag.nm.htm.

22. Barrow, Billy, Kevin Vineys, and Angeliki Kastanis. 2020. "Coronavirus' Spread in GOP Territory, Explained in 6 Charts." AP NEWS. June 30, 2020. https://apnews.com/article/7aa2fcf795533383 4e01a7f9217c77d2. 


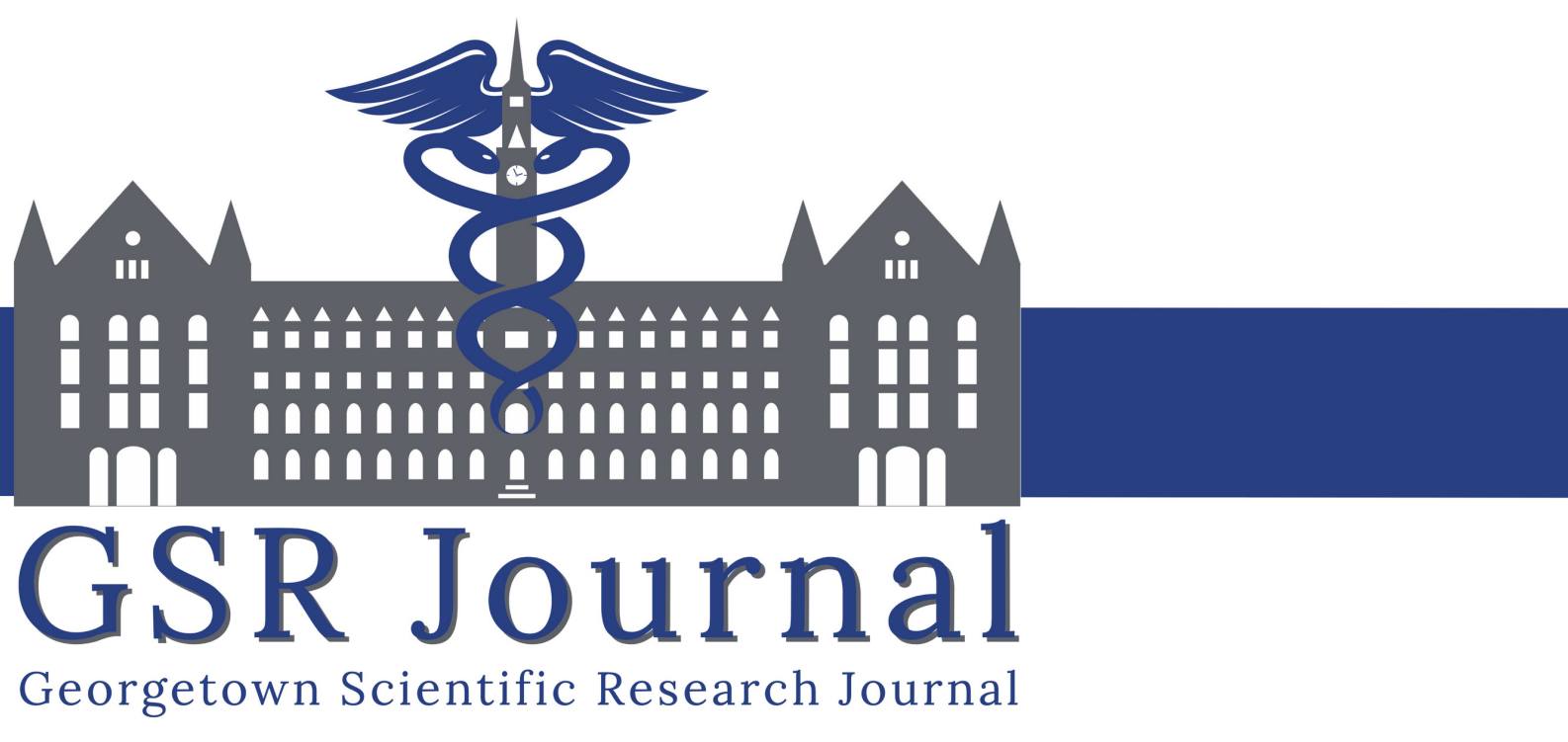

